\title{
Sport pro $=$ Twitter pro? - How soccer stars use Twitter at the height of their career
}

\section{Christoph G. Grimmer*}

Faculty of Economics and Social Sciences,

Institute of Sports Science,

University of Tübingen,

Wilhelmstraße 124, 72074 Tübingen, Germany

Email: christoph.grimmer@uni-tuebingen.de

*Corresponding author

\section{Galen Clavio}

\section{Media School,}

University of Bloomington,

601 E. Kirkwood Ave. Bloomington,

IN 47405-1223, USA

Email: gclavio2@indiana.edu

\begin{abstract}
This paper examines the usage of Twitter by professional soccer clubs and players in the context of a major sporting event. The study focuses on the UEFA Champions League Final in 2013, which featured two German football clubs. Nearly 300 tweets were coded via eight variables (author, content, date, language, media, mood, person and team). The results reveal considerable differences between the levels of activity and the players' Twitter performance. The clubs accompanied the season highlight in a communicatively extensive manner, but use Twitter in a strongly event-related manner. Concerning the players' activity, a classification into five categories was possible, based upon their overall levels of Twitter use. Numerous differences between each athlete's usage of Twitter were observed.
\end{abstract}

Keywords: Twitter; content analysis; soccer; social media; Champions League; Bayern Munich; Borussia Dortmund.

Reference to this paper should be made as follows: Grimmer, C.G. and Clavio, G. (2019) 'Sport pro = Twitter pro? - How soccer stars use Twitter at the height of their career', Int. J. Sport Management and Marketing, Vol. 19, Nos. 3/4, pp.161-183.

Biographical notes: Christoph G. Grimmer was a Lecturer in the Institute of Sports Science at the Eberhard Karls University, Tübingen in the Department of Sport Economics, Sport Management and Media Research, from 2013 to 2016. He received a graduate scholarship from the Federal State of Hamburg (HmbNFG) for his work about the relation between press spokespersons in the German Bundesliga and journalists. His research and teaching interests are focused on sports journalism, public relations, social media and international comparing analyses. From 2005 to 2009, he studied sports science (diploma) with specialisation in media and journalism at the University of Hamburg. 
Galen Clavio is an Assistant Professor at the Indiana University Bloomington. His research focuses on the influence of electronic and new media on the interactions between sport organisations and sport consumers. Some of the specific areas he researches are online sport fan communities, sports blogs, sport video games, and social networking media such as Twitter and Facebook. $\mathrm{He}$ is also interested in the concept of on-field performance as it relates to sales and marketing efforts in sport.

This paper is a revised and expanded version of a paper entitled 'Sport pro $=$ Twitter pro? - How soccer stars use Twitter at the height of their career' presented at 9th Summit of the International Association for Communication and Sport, Grand Rapids, USA, 11-13 March 2016.

\section{Introduction}

For several years, it has been a near-requirement for professional sports clubs, major sporting events, and athletes to possess their own internet-based information portals. Whether through web pages or social networking outlets, sport entities can determine which information they want to communicate to their publics. However, addressing target groups directly is difficult because the circle of users is often structured heterogeneously.

The conceptual architecture of Web 2.0, an online environment which both allows for and promotes interactivity and sharing between individuals, gives organisations and individuals the ability to focus their messages, and gives users the ability to take a more active role as consumers (Kaplan and Haenlein, 2010; Sanderson, 2011). ${ }^{1}$ Two technical developments have been relevant for the evolution of social media. ${ }^{2}$ Mobile access points such as smartphones and tablets, and amateur creation portals such as blogs allow for a democratisation of production goods. Everybody can create publicity and no longer must depend on traditional media (Kietzmann et al., 2011) to distribute that content. What initially began with Internet sites created by companies and private individuals has evolved via new and social media. At the same time, on every device with an Internet connection, content can be downloaded, used, shared, created, linked and processed. This process allows tablets, smartphones and other channels to operate as vehicles of both creation and reception. Thanks to the democratisation of publication- and reception-channels a carrier medium is no longer required. Content is available constantly.

The number of professional athletes recognising the possibilities inherent in digital communication is increasing. In this way, they gain empowerment through direct relation to their fans, strengthen identification and promote their own brand image (Schierl, 2011). Some soccer players engage agencies to care for their public image, establish communication channels and furthermore fill them with content. The German internationals Marco Reus, Mario Götze, Toni Kroos and Benedikt Höwedes are numbered among the customers of these agencies. As a part of public relations in sports, athlete PR is a young and upcoming discipline.

In recent years, research interest has been increasingly focused on the impact and use of new media, in particular social networks and blogs (Achen, 2015; Abeza et al., 2015; Bayne and Cianfrone, 2013; Brison et al., 2015; Eagleman, 2013; Hambrick, 2012; 
Hambrick and Svensson, 2015; Han et al., 2015; Hipke and Hachtmann, 2014; Hodge et al., 2015; Kang, 2015; Kian, 2015; Larkin and McKelvey, 2015; Lebel et al., 2015; Miranda et al., 2014; Moritz, 2015; Naraine and Parent, 2016; Olushola, 2015; Roberts and Emmons, 2016; Sanderson and Browning, 2015; Scott and Stanway, 2015; Walsh et al., 2013). These studies consider various media offerings and diverse aspects. They are often grounded in the users' perspective and based on the uses and gratifications theory by Katz et al. (1974).

As more and more athletes, teams, organisations, and fans make Twitter a regular part of their sport communication ritual, it becomes important to evaluate how those various segments are utilising the network. While there have been prior studies of athlete (e.g., Frederick et al., 2014; Frederick and Clavio, 2015; Hambrick et al., 2010; Hambrick and Mahoney, 2011; Hull, 2014a; Lebel and Danylchuk, 2012; Pegoraro, 2010), team, and organisation (e.g., Clavio and Walsh, 2013; Wang and Zhou, 2015) uses of Twitter, the constantly changing nature of the network continues to bring new users into the fold (e.g., Sanderson and Browning, 2015; Scott and Stanway, 2015; Watanabe et al., 2015).

Twitter usage in sport continues to evolve and mature. Periodic and exploratory evaluations of how new users, particularly those from previously unexplored populations, are using Twitter to communicate with publics is a valuable and necessary element of social media research in sports. The evaluation of major sporting events as an indicator of Twitter usage has found favour among social media researchers. For this study, evaluating how athletes utilise Twitter around one of the most popular professional sporting events in the world provides key insights.

\section{Review of literature}

\subsection{Self presentation}

Digital communication enables an exchange of messages with other individuals without a physical encounter, making it possible for individuals to create an identity based solely on digital presentation. A precondition of this process is a willingness to engage in self-expression. Goffman's (1959) work The Presentation of Self in Everyday Life was thus developed for face-to-face communication. He differentiated between front stage and backstage communication approaches. While front stage performances underlie cautious, deliberate and more cautious actions, backstage performances are generally more natural and genuine. People express their identity via verbal and non-verbal messages and reflect how to self-present the most credible image to others (Leary and Kowalski, 1990). Goffman illustrated that individuals continuously negotiate their individual self-presentation goals and the audience's expectations. Several studies have applied Goffman's idea of self-expression in recent studies reflecting the online environment (Bortree, 2005; Caplan, 2005; Gibbs et al., 2006; McMahon et al., 2016; Papacharissi, 2002).

The advent of online communication provides individuals better control over their self-presentation. Social networks can be employed to manage public impressions for both private and professional purposes. The lack of a physically present audience allows for messages to be configured ahead of time, rather than occurring in real-time (Hogan, 2010; Rui and Stefanone, 2013). A user can upload and spread information of all kinds 
on their network - especially short messages, photos, videos and links - in order to create a certain kind of goal-directed self-image.

\subsection{Athletes' self presentation on Twitter}

Twitter has become a news channel because of its hashtag function and the possibility of multiplying messages by re-tweeting (Kwak et al., 2010). ${ }^{3}$ Nearly 300 million active Twitter accounts are in use, and that number continues to rise. ${ }^{4}$ Twitter's dual processes of following and being followed make it distinct from other sources of news, allowing interactivity and customisation of information received. Each Twitter user curates their own feed, actively including items which interest them and passively excluding items and accounts which do not. Twitter possesses its own type of digital currency, via the utilisation of likes and retweets as items which illustrate social ties and communicative efficacy. While important within the digital architecture of Twitter, these variables are not the sole measure of success within the medium.

Professional athletes now possess a unique opportunity to maintain control over their individual brand images. Athletes no longer must rely on news media to reach audiences, and now have the chance to communicate directly with stakeholder groups such as sponsors and fans (e.g., Sanderson, 2008). Social media networks are an inexpensive option to establish and intensify relationships with supporters and customers, sometimes accompanied by troubling side effects like organisational monitoring and public censuring (Sanderson, 2009). Unlike traditional forms of media, social media facilitates symmetrical dialogue between athletes and audience members, instead of one-dimensional and purely parasocial relationship building (Grimmer, 2014). Pegoraro (2010) initiated a series of subsequently more and more differentiating and specialised studies on Twitter use. She assessed 49 athlete accounts of various sports over a 7-day period with results indicating that athletes predominantly responded to fans' queries and talked about their personal lives.

A similar approach investigated Twitter use of professional athletes, classifying athlete tweets into the categories of interactivity, diversion, information sharing, content, fanship and promotional (Hambrick et al., 2010). The highest percentage of the 1,962 analysed tweets fell into the interactivity category (34\%), followed by diversion (28\%) which involved non-sports-related topics, and information sharing (15\%) which was characterised by inside information about the own team, teammates, or sport. Thus, the athletes used Twitter as a complementary platform to traditional media formats in order to communicate more personally, enabling a stronger fan identification with the athletes. Hambrick and Mahoney (2011) analysed the role of celebrity athletes as marketers on Twitter. Serena Williams and Lance Armstrong wrote promotional messages $12 \%$ of the time, representing endorsements for sport-related equipment with other consumer products.

Clavio and Kian (2010) used athlete-focused Twitter communication as the focal point for their study. They questioned followers of a retired female professional golfer. The study identified organic fandom (personal affinity for athletes), functional fandom (focus on athlete's sporting exploits) and interaction (part of a community and interacting with the athletes) as dimensions of gratification among users of the Twitter feed.

Lebel and Danylchuk (2012) explored gender differences in professional athletes' self-presentation in the context of Twitter. They found similar image construction patterns being used by both male and female tennis players, although significant 
differences appeared with regard to the applied self-presentation strategies. While female athletes were found to spend more of their time performing the role of brand managers (formal acknowledgements associated with positive image) than their male counterparts, male athletes put significantly more effort into their roles as sport fan (discussion of non-tennis athletes and other sports). According to the authors, females acting consciously reflects gender norms.

Sanderson (2013) analysed how rookies in the MLB, NBA, NFL and NHL used Twitter for image building purposes. The study found that these athletes used Twitter in several ways beyond sports-related content. For instance, they asked fans for restaurant recommendations, tweeted personal information about their private lives, and shared their cultural preferences. Sanderson (2014) also explored how MLB professional Logan Morrison used Twitter for self-presentation purposes. Morrison appeared sarcastic and self-deprecating. The athlete's communication ran counter to the club's preferences, based upon their public reactions critical of his social media use.

Building on this, Frederick et al. (2014) investigated athletes' communication styles on Twitter. They found out that athletes promote social and parasocial relationships relatively equally. By communicating with lay persons most frequently, they "break down traditional barriers that once existed between themselves and the everyday fan" (p.93). The study evaluated the different types of tweets being used by athletes, classifying tweets directed specifically at audience members as social in nature, and broadly directed tweets as parasocial. The study evaluated athletes' ability to control the kind of message being delivered and the nature of interaction with fans and users [everyday fan as 'voyeur' or 'digital acquaintance'; Frederick et al., (2014), p.96], ascribing the main potential for relationship formation to the media persona.

A study was conducted by Hull (2014a), who examined how professional golfers used Twitter during the Masters tournament. The results suggest that fans receive front stage and backstage insights into the athletes' lives. The most important conclusion from the study is that the golfers provide fans a personal view of their life (i.e., backstage) while simultaneously maintaining a professional persona that can serve as testimonial and please sponsors (i.e., front stage). Hull (2014b) also explored how college athletes at UNC-Wilmington used Twitter to help save their swimming and diving teams from being eliminated. His content analysis of 1,775 tweets by 25 athletes and interviews suggests that the athletes used Twitter to demonstrate community support through social media.

Jensen et al. (2014) performed a study which questioned the ultimate extent of social media's reach and popularity within sport. Their results showed that long-term success (program's prestige) indicated by facets such as tradition, overall on-field success, and current demand for the program are most influential factors for Football Bowl Subdivision head football coach popularity on Twitter. Variables like average attendance for the recent season, stadium capacity, all-time bowl appearances and all-time wins significantly correlate with the number of followers that each coach possesses on Twitter. However, the coach's length of time on Twitter correlated most with followers, and the total amount of tweets generated by the account significantly affected the number of followers. Hence, activity and interaction with fans and alumni may realise increased reach and popularity.

Apart from athletes, Weathers et al. (2014) investigated sports broadcasters Erin Andrews' and Kirk Herbstreit's self-presentation on Twitter during the 2012-2013 college football season. According to the results, both broadcasters self-expressed along 
traditional gender lines. While Herbstreit centred on expert opinion and sports information, Andrews focused on personal information such as entertainment and fashion. More recent studies dealt with the users' perspective on athletes' self-presentation and brand extensions as well as users' information and communication habits or media consumption motives (Burk et al., 2016; Haugh and Watkins, 2016; Kang et al., 2015; Sanderson and Gramlich, 2016; Wakefield, 2016; Walsh and Williams, 2016; Watanabe et al., 2015, 2016).

Most of this work has covered North American sports. While this has been beneficial in broadening the literature on self-presentation in general and athletes' self-presentation in particular, it is important to focus on other international sports contexts as well. In this regard, Europe is just one realm alongside the Asian or African context - however, it is a very relevant one due to the popularity of soccer in Europe and across the world.

The most prominent European sports star is the Portuguese soccer player Cristiano Ronaldo, whose follower numbers ranked 13th worldwide among all celebrities on Twitter at the beginning of 2016. Ronaldo's profile attracted about 40 million followers (Twittercounter.com, 2014). While Twitter follower numbers must be approached cautiously due to fake or inactive accounts (Billings, 2014), the large numbers of interested followers indicate how significant Twitter has become as a means of communication, and as a medium for distributing information about celebrities, clubs and sports athletes. In that vein, we explored soccer players' self-presentation on Twitter to gain more insight into how they apply this important communication channel in the context of a major sporting event, and searched for parameters that may have an influence on the tweeting activity.

\section{Methodology}

\subsection{Research questions}

The strong growth in the market for interactive communication demonstrates the importance of analysing the development and usage of social media in sports. It is obvious that social media provide a variety of opportunities for marketing communications, in particular for athletes, clubs, organisations, and sports public relations (PR) workers. However, compared to the English-speaking world, Twitter in Germany to date seems to be an underestimated, underutilised, and relatively unexplored channel, particularly when compared to Facebook (Nölleke et al., 2016).

Internationally renowned sporting events guarantee worldwide attention and open up the chance for social media accounts to reach large audiences. Within the business realities of global sport, major or mega events are often as important for their marketing and sales implications as they are for the chances to win trophies or medals. Based upon the review of literature included above, and against the background of the importance of first UEFA Champions League final to feature two teams from Germany, the following research questions were used to examine how the communication channel Twitter is used in context of a major sporting event:

RQ 1 How do soccer players use Twitter in the context of a major sporting event (frequency, content, mood, and media)?

RQ 2 Which variables have an influence on tweeting frequency and tweet focus? 


\subsection{Sample}

The Twitter activity of players from the clubs Bayern Munich and Borussia Dortmund (BVB) was examined in the context of the 2013 UEFA Champions League final between both teams. The final took place in Wembley Stadium in London on 25th May 2013. This match was broadcast in more than 200 countries worldwide, and the game broadcast saw an average viewership of 150 million people. According to UEFA figures, more than 360 million total worldwide viewers watched at least some part of the game (Ashby, 2013). Because some players were not verified by Twitter as owning their feeds, the official accounts have been matched with BVB and Bayern Munich to make sure that only authentically controlled channels would be analysed. Identity theft is widespread, and there are some fans who tweet in the name of soccer professionals.

At the beginning of data collection there were 18 observed channels. ${ }^{5}$ Two players established a personal account during the collection period: BVB captain Sebastian Kehl's account was established on May 22nd, while Bayern Munich defender Holger Badstuber started an account a week later. The addition of these two players increased the sample to $\mathrm{n}=20{ }^{6}$

\subsection{Data collection}

Content analysis was employed to categorise and analyse the players' tweets. First, players' Twitter messages were considered qualitatively in order to generate categories from the present material for subsequent tweet analysis (data coding). In total, eight variables were used in order to evaluate Twitter use of soccer professionals with respect to the first research question. Besides team, player, and date as basic information to assess the activity and frequency of twitter usage, variables for originator, content, language, mood, and media integration were used. These variables served the purpose of exploring whether messages were tweets or retweets, which topics were specifically communicated, whether the players used German, English, or other languages, if the tweets had a positive, neutral or negative focus, if media or links were integrated into the tweets, and what media or links were used. When a player utilised different languages within one message, it was only coded once, and by the priority of German, then English, then other languages.

The investigation period began on the 15th of May, 2013 and ended on the 4th of June, 2013. The examination period spanned 21 days, and included ten days before the final, the day of the final and ten days after it. Taken as a whole, three weeks of tweets were captured and analysed. ${ }^{7}$ Before the analysis, the confirmed Twitter accounts of the players were investigated.

\subsection{Data analysis}

Of a subsample of 295 total messages sent, 275 (93.2\%) were tweeted by Bayern Munich players, while the BVB players only tweeted a total of 20 times during the three weeks of observation. In addition to quantitative analysis of several variables, player tweets were examined for content and tone.

A qualitative content analysis seemed the appropriate method to analyse the Twitter accounts adequately. The researchers felt the study should not limit itself to purely 
quantitative analysis, but rather should regard and represent the online communication processes being used by the athletes more precisely. The aim of the study was to provide a general view of Twitter usage by athletes in the context of the Champions League final, and while solely utilising quantitative analysis provides a basic look at similarities and differences, the integration of qualitative analysis allows for a more well-rounded evaluation of Twitter usage by the individuals being evaluated.

Statistical calculations were applied to address the second research question. On account of the comparatively low number of assessed players who communicated via Twitter within the three-week investigation period $(\mathrm{n}=17)$, statistical calculation for influential factors on activity and tweet focus was restricted.

Due to the lack of tweets from BVB players, the applied statistical calculations were limited to the players of Bayern Munich ( $n=14 ; 275$ tweets at maximum). Since interval scaling, homogeneity of variance and normal distribution were present, t-tests were performed as statistical analysis with the influence of age, nationality, and position tested for their influence on Bayern players' Twitter activity. The same variables were tested for their impact on tweet foci in Bayern player's tweets. Due to language barriers and limitations on German and English language messages, the number of tweets examined was reduced to $n=180$. Because no specific assumption of statistical distribution was presumed - for instance, there is no plausible reason why younger or German players should communicate other topics in this case than older or non-German players - a non-parametric u-test was conducted.

\section{Results}

A preliminary examination of the accounts to be analysed yielded interesting results. This early appraisal showed that of the four 'official' coaches for both teams, none of them had an official Twitter account. Twenty of the 60 total protagonists had their own profile (33.3\%). The ratio on the side of BVB is $20.0 \%$, with Champions League winner Bayern Munich $46.7 \%$. Excluding the coaches, more than half of the Bayern players had their own Twitter profile $(53.8 \%)$, while $23.1 \%$ of BVB players had one.

Midfielders appeared to take advantage of Twitter usage to a greater degree than other players, with a bit more than half of the midfield players for both teams owning an account (52.4\%). German national team goalkeeper Manuel Neuer was the only one of the eight goalkeepers in the analysis who possessed a Twitter account (14.3\%). Roughly every third defender (31.3\%) and striker (37.5\%) used Twitter.

\subsection{Players' Twitter performance}

RQ1 asked about players' Twitter usage in the context of a major sporting event. In looking at the content production of the players for both teams, an interesting pattern emerged. Half of the BVB players sent no messages during the period of investigation, but each Bayern player sent at least two messages. The majority of players active on Twitter sent between one and seven tweets per week. Players Luiz Gustavo, Claudio Pizarro and Rafinha used Twitter during the week of the Champions League more than in the other two weeks. Players Dante, Jerome Boateng and especially Anatoliy Tymoshchuk were the most active tweeters, each with an average of more than ten tweets per week. 
Tweets in this sample appeared to coincide with major events, including the aforementioned finals and the last two scheduled match days in the German Bundesliga. Bayern Munich player usage of Twitter exceeded BVB player usage, in part because 14 Bayern players utilised the service, as compared to only six BVB players, with only three of those six actively participating. During the day after the Champions League final, Bayern players tweeted an average of 4.1 times, which represented the top peak value of any day in the sample. ${ }^{8}$ The BVB players did not tweet in the days after their Champions League defeat. Five groups of Twitter usage were identifiable among the observed players in the sample.

Table 1 Amount of players' Twitter messages

\begin{tabular}{lcccccc}
\hline \multirow{2}{*}{ Activity level } & Player & Club & $\begin{array}{c}\text { 1st } \\
\text { week }\end{array}$ & $\begin{array}{c}\text { 2nd } \\
\text { week }\end{array}$ & $\begin{array}{c}\text { 3rd } \\
\text { week }\end{array}$ & Tweets \\
\hline Ultra user & Tymoshchuk, Anatolyi & Munich & 10 & 35 & 12 & 57 \\
Super user & Bonfim, Dante & Munich & 13 & 14 & 16 & 43 \\
& Boateng, Jerome & Munich & 2 & 26 & 13 & 41 \\
Active user & Gustavo, Luiz & Munich & 2 & 16 & 6 & 24 \\
& Martinez, Javi & Munich & 7 & 4 & 12 & 23 \\
& Pizarro, Claudio & Munich & 3 & 16 & 2 & 21 \\
& Rafinha & Munich & 4 & 11 & 5 & 20 \\
Selective user & Shaqiri, Xherdan & Munich & 1 & 4 & 7 & 12 \\
& Mandzukic, Mario & Munich & 3 & 3 & 6 & 12 \\
& Alaba, David & Munich & 3 & 2 & 5 & 10 \\
& Sahin, Nuri & Dortmund & 6 & 3 & 0 & 9 \\
& Kehl, Sebastian & Dortmund & 2 & 5 & 0 & 7 \\
& Götze, Mario & Dortmund & 1 & 1 & 2 & 4 \\
& Schweinsteiger, Bastian & Munich & 0 & 1 & 3 & 4 \\
& Neuer, Manuel & Munich & 1 & 1 & 1 & 3 \\
& Kroos, Toni & Munich & 0 & 1 & 2 & 3 \\
& Badstuber, Holger & Munich & & 2 & 0 & 2 \\
& Subotic, Neven & Dortmund & 0 & 0 & 0 & 0 \\
& Leitner, Moritz & Dortmund & 0 & 0 & 0 & 0 \\
& Reus, Marco & Dortmund & 0 & 0 & 0 & 0 \\
\hline \multirow{3}{*}{ Non-user } & & & & & &
\end{tabular}

Table 1 shows five observed categories of activity for player tweets, as described below:

- Non-user: Superficially, the term 'non-user' seems to be contradictory in nature, since BVB players Subotic, Leitner, and Reus all possess official Twitter accounts. However, they did not use them to disseminate messages within the observation period. Because Twitter can be used for accessing information, it is possible that the players used their accounts solely to inform themselves.

- Selective user: Half of the soccer players observed using Twitter were included in this category. They use Twitter quite conservatively, rarely sending out messages. 
Goalkeeper Manuel Neuer, who was placed in this category, sent only one tweet in each of the three observation weeks.

- Active user: Luiz Gustavo, Javi Martinez, Claudio Pizarro and Rafinha can be counted in the group of active users. On average, each of these players created one message per day, a rate that exceeded the average of the sample of observed players. The four players included in this category were born in countries other than Germany.

- $\quad$ Super user: Bayern Munich's defenders Dante Bonfim and Jerome Boateng constitute an intermediate category that lies above the group of active users but considerably below the most active player, Anatolyi Tymoshchuk. They can be described as super users, because on average they send two tweets per day each. Hence, they manifest an increased level of activity in comparison to the other players.

- Ultra user: The Ukrainian international Tymoshchuk sat on the bench during the whole Champions League final. In the German FA Cup final, he came into the game for the last seven minutes. However, through the entire examination period, he used his Twitter account more than any other observed individual.

The results show that players can be distinguished from one another through both qualitative and quantitative examination in terms of their Twitter usage. Some players use Twitter only occasionally, while others disseminate information more regularly and broadly. Figure 1 illustrates player Twitter usage for both clubs during the observation period.

Figure 1 Players' tweet performance of both clubs in total (tweets/day) (see online version for colours)

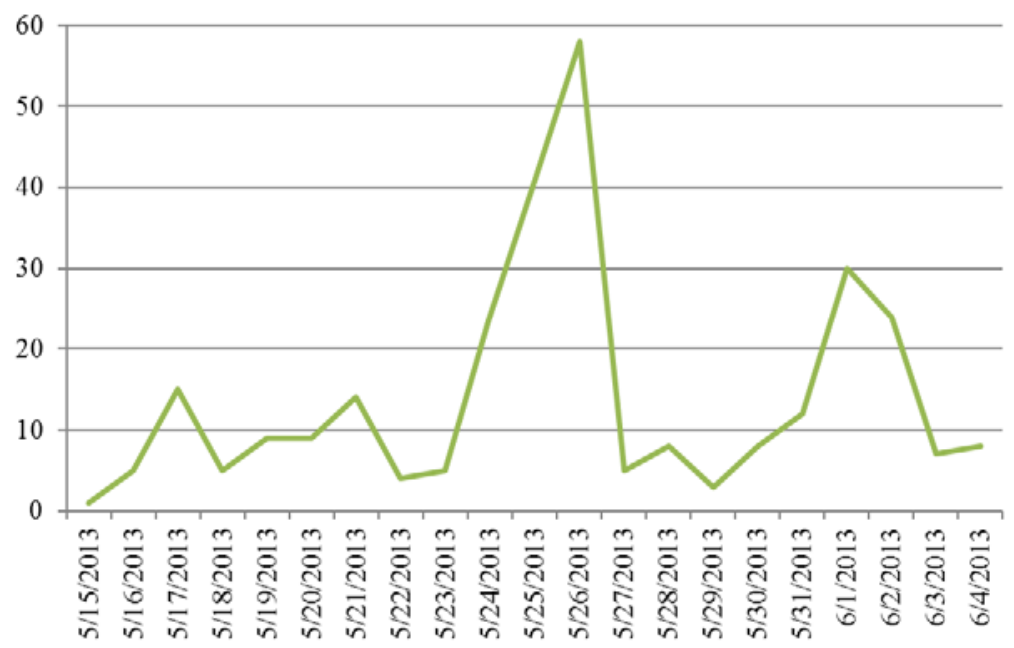

We have already established that the dates of the Champions League final and the German FA Cup final stand as the biggest outliers in this data set. Also of interest are two specific dates where the number of observed tweets exceeded ten per day. Those dates were the 17th of May and the 21st of May. In looking at these two dates closely, the 
greater concentration of tweets appears to emanate from two persons. First, a game was played on May 18th between Bayern Munich and league opponent Borussia Mönchengladbach, which saw Bayern defender Dante play against his former team. On his Twitter feed, he expressed pleasant anticipation the day before the game, and thanked fans and the organisation for the successful time they had together when he played there ("Returning to the place where the doors were opened where I have many friends and I will never forget everything they did for me." / Dante Bonfim, 17th May 2013).

On May 21, Tymoshchuk published some photos of a gala reception in Munich's town hall. Six out of 14 tweets that day were sent by the player, who distributed the messages mostly in German and his national language of Ukrainian. That circumstance became a problem for the coding, which had to be reduced to language translation issues. 9

Observed tweets were spread across multiple languages. About two thirds of the tweets were written in German (34.6\%) or English $(29.2 \%)$. Out of 295 total coded messages within the three observed weeks, 102 tweets were written in German and 86 were written in English. Tweets in languages other than German or English accounted for 107 of the total $(36.3 \%)$. When a player utilised different languages within one message, it was only coded once and by the priority German, English, other language.

\subsubsection{Tweet originators}

Twitter offers the possibility for tweets and retweets. Correspondingly, messages can be distributed and forwarded. Additionally, one has the option to have conversations so that answers to tweets of others appear as one's own tweets. The analysis shows a high number of own tweets (238 out of $295 ; 80.7 \%$ ). Nearly every fifth message was a retweet of another user $(57 ; 19.3 \%)$.

\subsubsection{Tweet content foci}

The study looked further into the content focus of player tweets, specifically whether their tweets tended to focus on themselves, their teammates, or on the team. Because of language barriers and incomprehensible meaning of some tweets, nearly one third of the distributed messages could not be evaluated.

Event tweets included messages relating to the Champions League and German FA Cup finals, but also other occurrences. For instance, Sebastian Kehl's message about the take-off of the team flight to London for the Champions League final was classified as an event. The example indicates a difficulty in the adequacy of the descriptive power of some categories. The message of the flight concerned the team, but the coder decided the departure was most relevant - without the occurrence (departure) itself, the tweet would not have been realised at all, at least not in that way.

Remarkably, not a single observed tweet dealt with the team's opponent during the whole observation period. Five tweets were classified as advertising, with three of those tweets attributable to BVB player Nuri Sahin, who retweeted the messages of a Turkish airline.

Figure 3 illustrates a qualitative assessment of player tweets gathered in the observation period. For the following illustration all tweets were excluded that could not be evaluated in conjunction with the tweets' content due to language barriers. Subsequently, the graphic shows only players with at least five or more coded tweets. 
Figure 2 Thematically tweet focus (players of both clubs) (see online version for colours)

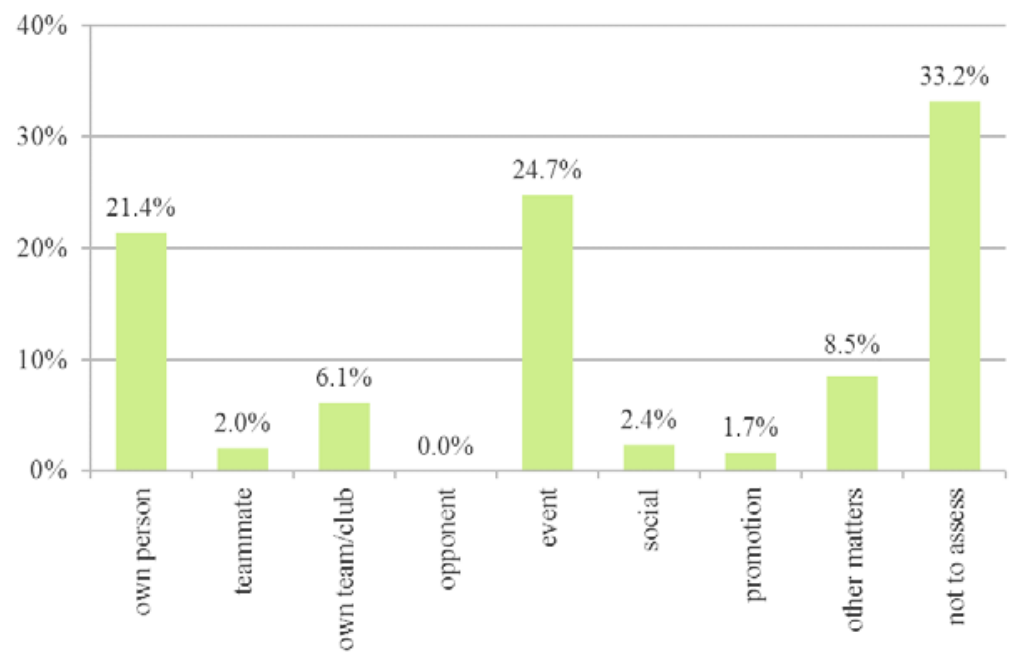

Figure 3 Thematically tweet focus (differentiated by players) (see online version for colours)

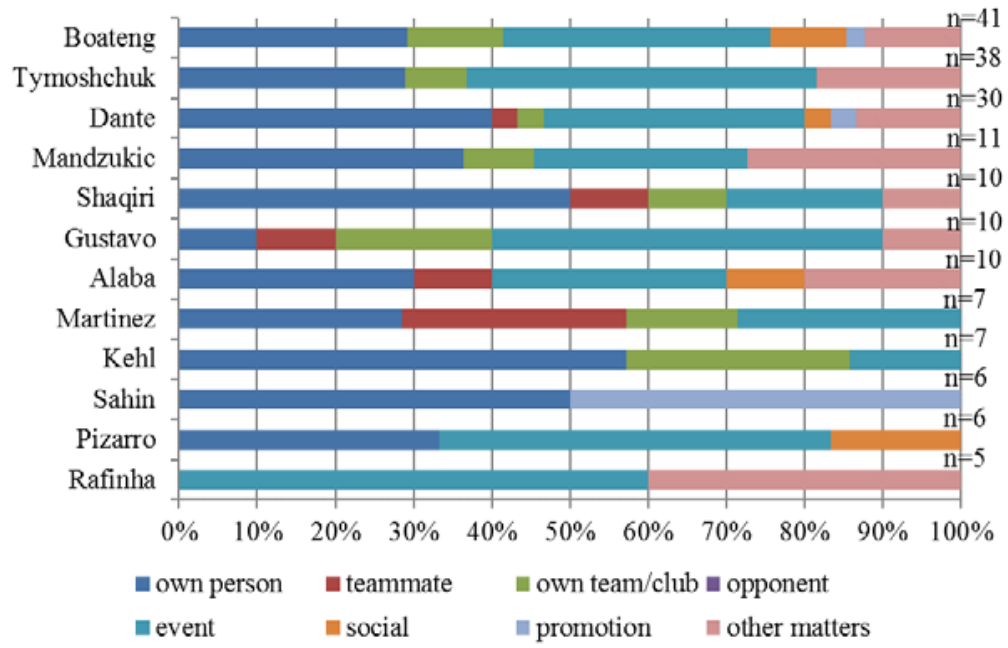

Most of the players appear to focus on themselves in their messages. This is particularly noticeable in the tweets of Kehl. Simultaneously, he is the player who tweeted about his own club the most. It is interesting that Bayern midfielders Javi Martinez and Luiz Gustavo broach the issue of their teammates, and could be classified as communicative team players away from the pitch. For instance, Martinez tried to comfort defender Holger Badstuber after his second cruciate ligament rupture within seven months ("Get well soon Holger!" / Martinez, 18th May 2013).

Two Bayern Munich players, Gustavo and Dante, were forced to miss the FA Cup final due to not receiving a release from the Brazilian soccer association allowing them to play the game. After Bayern's victory in that game, its players showed the jerseys of the 
two Brazilians as well as an injured teammate, and Gustavo used Twitter to thank his fellow players for their comradely gesture.

\subsubsection{Tweet mood}

There was an attempt to discern player mood and emotion through analysis of the observed tweets. The emotional charge of the messages was of great interest in the analysis. The variable was consciously named 'mood' because it requires subjective judgment.

Because of the language barrier, several messages could not be evaluated (34.2\%). Nearly one quarter of the tweets were found to be neutral (22.4\%), while slightly less than half of the tweets conveyed positive content (43.1\%). This ratio is likely due to the fact that the majority of the tweeting came from the Bayern players who won the final, their second Champions League final win in a short period. BVB player Mario Götze sent the only negative message, which concerned his injury that prevented him from playing in the Champions League final $(0.3 \%)$.

\subsubsection{Media integration and linking}

During the data collection, the researchers took into account how the players connected their created content to other communication channels via media and link integration. This data was evaluated for whether players were integrating personal communication platforms. Embedding photos was found to be very popular with players, as $41.7 \%$ of the observed tweets were combined with a picture, and an additional $7.8 \%$ of tweets were linked to the photo-sharing platform Instagram. However, only ten out of 295 analysed player tweets had a connection to Facebook (3.4\%).

Thus, cross-media content strategies, in this case interpreted as the tweeter combining different channels (i.e., Twitter-Facebook, Twitter-Instagram) was proportionately less popular among the observed group. Six of the ten messages with connection to Facebook were attributable to Toni Kroos and Mario Götze. Both players set themselves apart from the others by advertising their Facebook profiles. In the end, Kroos only tweeted three times during the observation period but used all three of those tweets to link to his Facebook page. Götze tweeted four times total, with three of those messages promoting his Facebook page link. Additionally, 3.1\% each included either a video sequence or another sort of link. The remaining $41.0 \%$ of tweets without any kind of media or link.

\subsubsection{Detailed analysis: players most likely to link}

Specific attention was paid to which players showed the most active media usage, which in this case was focused on players including links to other content in their tweets. Approximately $60 \%$ of the observed players integrated links to other media in their tweets. Of the 17 players who included links in their tweets, three included links in all of their tweets. These results are presented in Table 2.

Bayern Munich fan favourite Xherdan Shaqiri is part of the group of media users and 'linkers'. Three quarters of his messages were enriched with a video, picture or Instagram link. At the season's closing ceremony on Munich's Marienplatz, Shaqiri tweeted a celebration photo which shows him with his teammates Diego Contento, Rafinha and Tom Starke. 
Table 2 Most media-related and linking-joyous players

\begin{tabular}{lc}
\hline Player & Tweets \\
\hline Götze, Mario & $100 \%$ \\
Badstuber, Holger & $100 \%$ \\
Kroos, Toni & $100 \%$ \\
Tymoshchuk, Anatolyi & $89.5 \%$ \\
Kehl, Sebastian & $85.7 \%$ \\
Shaqiri, Xherdan & $75.0 \%$ \\
Mandzukic, Mario & $75.0 \%$ \\
Bonfim, Dante & $69.8 \%$ \\
Boateng, Jerome & $51.2 \%$ \\
Alaba, David & $50.0 \%$ \\
Schweinsteiger, Bastian & $50.0 \%$ \\
Sahin, Nuri & $44.4 \%$ \\
Rafinha & $35.0 \%$ \\
Martinez, Javi & $34.8 \%$ \\
Neuer, Manuel & $33.3 \%$ \\
Gustavo, Luiz & $33.3 \%$ \\
Pizarro, Claudio & $19.0 \%$ \\
\hline
\end{tabular}

\subsubsection{Statistical influence on tweeting frequency and tweet foci}

RQ2 asked about variables having an influence on tweeting frequency and tweet foci. Taking into account the small sample size, the professionals were separated into two groups of the same size. This was not a problem within the age group, as one younger group comprising players aged 20 to 26 years and one older group including players aged 27 to 34 years were used (each group contained $n=7$ players). Because midfielders had been strongly represented $(n=7)$, all other positions were summarised to one category. This was not possible with the nationality variable.

Table 3 T-test on influence of variables on Bayern players' tweet activity

\begin{tabular}{lcccccc}
\hline Variable & Group & $N$ & Mean & Std. dev. & Std. err. & $T$ (sig.) \\
\hline Age & $20-26$ & 7 & 16.43 & 13.867 & 5.241 & $-.694(.501)$ \\
\multirow{3}{*}{ Nationality } & $27-34$ & 7 & 22.86 & 20.211 & 7.639 & \\
& Germany & 5 & 10.60 & 17.009 & 7.607 & $-1.566(.143)$ \\
\multirow{2}{*}{ Position } & Other nationalities & 9 & 24.67 & 15.636 & 5.212 & \\
& Midfield & 7 & 19.00 & 18.690 & 7.064 & $-.136(.894)$ \\
& Other position & 7 & 20.29 & 16.570 & 6.263 & \\
\hline
\end{tabular}

Table 3 shows that older players sent an average of six tweets more per player than younger professionals during the investigation period (22.86 vs. 16.43). Regarding the impact of the playing position, midfield players sent one tweet less than athletes on other positions. The greatest difference between players was with respect to nationality. Nine 
players from outside of Germany communicated nearly 25 tweets per player during the 21 investigational days, whereas German players, with 10.6 tweets, had on average just one tweet every second day. However, the observed differences were not significant for any of the variables.

Concerning tweet foci, there was just one variable influential for each topic 'own person', 'team and teammates', and 'event'. According to this variable, older players focus significantly more often on themselves and on the event than did younger players. In terms of the variable 'team and teammates', the players' nationalities had an impact. Foreign (non-German) players focus more extensively on their team and teammates. The third controlled variable (position) has no significant influence on tweet content. However, average values indicate that midfield players talked less about themselves and, instead, more about the whole team or their teammates.

Table 4 U-test on influence of variables on Bayern players' tweet foci

\begin{tabular}{|c|c|c|c|c|c|c|}
\hline Topic & Variable & Group & $N$ & Mean & Std. dev. & Sig. \\
\hline \multirow[t]{6}{*}{ Own person } & Age & $20-26$ & 7 & 3.29 & 4.231 & $.029 *$ \\
\hline & & $27-34$ & 7 & 4.14 & 5.242 & \\
\hline & Nationality & Germany & 5 & 2.40 & 5.367 & 1.000 \\
\hline & & Other nationalities & 9 & 4.44 & 4.275 & \\
\hline & Position & Midfield & 7 & 3.14 & 3.891 & .902 \\
\hline & & Other position & 7 & 4.29 & 5.469 & \\
\hline \multirow[t]{6}{*}{ Team and teammates } & Age & $20-26$ & 7 & 2.14 & 1.676 & .898 \\
\hline & & $27-34$ & 7 & 1.00 & 1.155 & \\
\hline & Nationality & Germany & 5 & 1.40 & 2.074 & $.038^{*}$ \\
\hline & & Other nationalities & 9 & 1.67 & 1.225 & \\
\hline & Position & Midfield & 7 & 1.86 & 1.215 & .209 \\
\hline & & Other position & 7 & 1.29 & 1.799 & \\
\hline \multirow[t]{6}{*}{ Event } & Age & $20-26$ & 7 & 4.29 & 4.461 & $.029 *$ \\
\hline & & $27-34$ & 7 & 6.00 & 5.508 & \\
\hline & Nationality & Germany & 5 & 4.80 & 5.215 & .383 \\
\hline & & Other nationalities & 9 & 5.33 & 5.025 & \\
\hline & Position & Midfield & 7 & 5.00 & 5.385 & .710 \\
\hline & & Other position & 7 & 5.29 & 4.786 & \\
\hline \multirow[t]{6}{*}{ Other issues } & Age & $20-26$ & 7 & 2.14 & 3.625 & .060 \\
\hline & & $27-34$ & 7 & 2.71 & 2.812 & \\
\hline & Nationality & Germany & 5 & 2.00 & 4.472 & .456 \\
\hline & & Other nationalities & 9 & 2.67 & 2.398 & \\
\hline & Position & Midfield & 7 & 1.71 & 2.563 & .318 \\
\hline & & Other position & 7 & 3.14 & 3.671 & \\
\hline
\end{tabular}




\section{Discussion}

This analysis focused on how Twitter is used by soccer players in the context of a major sporting event, with the 2013 Champions League final serving as a backdrop. Particular attention was focused on characteristics of the players' uses of Twitter, and statistical evaluation of the Twitter activity and tweet foci of Bayern players. Referring to Goffman's (1959) presentation of self, most of the players analysed in this sample communicated cautiously on the digital front stage of Twitter (Hull, 2014a). Especially positive or neutral messages are distributed, indicating an interrelation. Only one tweet deemed as negative in tone was observed during the three week period used for this analysis. More than $40 \%$ of the tweets were positive, and nearly one quarter of the tweets were neutral. The mood results were likely influenced by the fact that most of the tweets were sent by players of Bayern Munich, the team that won both cup finals that occurred during this period.

It can be assumed that the soccer players of both teams analysed in this sample negotiated their individual self-presentation goals and the audience's expectations. However, across athletics, not every player has seen an adding value in participating on Twitter (Sanderson, 2008). Comparing BVB's and Bayern Munich's players, it was Bayern's squad which was the more communicative of the two. Fourteen out of their 26 players had a publicly accessible account, compared to only six of their BVB colleagues. By sending 275 tweets in total, each player of the victorious Bayern Munich tweeted nearly 20 messages, in contrast to BVB's players who sent only 20 total tweets, and with three of BVB's players entirely inactive on Twitter during the observed period. Thus, during this observed period, not every athlete made use of the social media capabilities such as dialogue, engagement, and relationship building with fans (Frederick et al., 2014; Grimmer, 2014; Pegoraro, 2010).

Concerning activity level, a classification into five categories was possible. The spectrum of activity ranged from non-users to ultra users. Between these extremes, selective, active and super users were differentiated. These classifications naturally extend the work of prior scholars (e.g., Hambrick et al., 2010; Lebel and Danylchuk, 2012) by providing a baseline conceptualisation of activity on Twitter for athletes. While further exploration of these categories is necessary, the ability to separate athletes as Twitter users into specific quantified typologies could assist both scholars and practitioners in explaining how Twitter works in this context. Fans are only able to participate in a player's career highlight on Twitter if the player is using the service, and in the case of this analysis, fans were only able to engage with a select number of players, and to varying degrees.

It should be noted that socio-cultural origins may have influenced the level of Twitter activity with some players, as all players in the upper ranks of this activity spectrum have an international background. Ukrainian player Anatolyi Tymoshchuk tweeted in three languages, including his native Ukrainian, German, and English. However, international origin is not the only explanation for high usage of Twitter, as two observed BVB players (Sahin and Subotic) are of foreign origin but did not engage in high usage.

Results show that the soccer players addressed audience expectations (Clavio and Kian, 2010; Hambrick et al., 2010). Events and the individual person are consistently the central element presented in Twitter messages from players (Frederick et al., 2014; Hull, 2014a; Lebel and Danylchuk, 2012). The player's club is of rather subordinated interest, teammates are hardly present in player's messages, and the opponent played no part 
(Hambrick et al., 2010). Compared to traditional mainstream media content, the content of player tweets showed a very personal method of communication. Fans are provided insight into athlete lives, experiences, and moods (Pegoraro, 2010; Sanderson, 2013). Additionally, fans have the chance to get in touch with their sports icons, both directly (through tweeting) and indirectly (through observing the player's tweet). This quite personalised and unfiltered communication method enables stronger identification and a more sustainable relationship between soccer players and their fans. The statistical calculations revealed important differences between German athletes and players from abroad. The focus of the observed tweets did possess some significant differences, as players from abroad communicated more extensively on the own team and their teammates than did German athletes. Thus, foreign players turned out to be digital team players, talking significantly more about the team and their teammates than did German-born players. Younger players talked less about themselves and the event than did older players.

In terms of activity, none of the variables age, nationality and playing position turned out to be significant. However, older players (27-34 years) were observed to be more active than younger ones (20-26), and non-German players were twice as active on Twitter as their German counterparts ( 24.7 versus 10.6 tweets). There were hardly any observed differences between midfielders and players on other positions.

More than one third of the sent tweets were not written in either the German or English languages. The percentage of international tweets in the sample was therefore above the percentage of German-language tweets. This result seems surprising because the observation took place in the context of a purely German Champions League final. It may demonstrate the ultimately existent reservation of German professionals with regard to the medium of Twitter (Nölleke et al., 2016), or it might point towards a growing need to communicate to multiple external nationalities within the context of sport communication in social media.

\section{Conclusions}

This paper analyses the Twitter activity of soccer players ahead of, during, and after the UEFA Champions League final took place. The fact that this match contained two teams from the same country, but involved a multi-ethnic roster of players and a worldwide audience of fans, all lead this event and the social media activity surrounding it to be an excellent subject for study.

Because not every account had been verified, the players' official accounts have been matched with the clubs' social media managers. The investigation period focused on the days surrounding the main event. Despite of relatively short time span, nearly 300 tweets were found to have been produced, and were subsequently analysed for content through the utilisation of eight variables (team, player, date, originator, content, language, mood, and media integration). The results of this analysis demonstrated considerable differences between players in regard to usage and activity (frequency of sending messages).

Despite the context of the Champions League final and the platform it provides athletes for additional attention from fans, it appears that many athletes, particularly on the defeated team, were not interested in, or willing to, leverage that opportunity into strengthening relationships with fans or gaining additional followers on Twitter. While 
players from the winning Bayern Munich team were often active on Twitter, the losing side had very little post-match Twitter activity. From a communication management perspective, it seems to be a challenge in particular for defeated players and teams - most likely not just in soccer but also in other sports - to handle their frustration communicatively and use this moment of disappointment to reveal themselves as good losers.

For elite athletes, there does not yet seem to be a consensus on the 'right way' to communicate via social media. All of the soccer players observed in this study appeared to have their own individual method for using Twitter. It is beneficial insofar that the players' communication forms differ between the different players, and hence involve diversity and variety. Statistical differences in terms of engagement and tweet foci were identified. The findings allowed conclusions to be drawn with respect to underutilised opportunities and specific challenges for the defeated team. Interestingly, the playing position had no influence on the observed activity level and tweet foci. It is possible that players do not consider themselves as distinct from each other regardless of their position. However, the opportunity for players to provide more specialised communication based on position, such as how they experienced the match from their position on the pitch, the decisive moments (goals, fouls etc.), and the circumstances on match day and in the playing venue, may represent an untapped opportunity for player brand extension and fan interaction.

\subsection{Limitations}

This study was exploratory in nature, and therefore has limited validity and generalisability. The sample of roughly 300 tweets can be regarded as problematic, but the authors had no influence on this number as it covers a relatively short examination period that is owed the specific context of the chosen Champions League final as event for this investigation. A long-term study that deals with Twitter usage of elite athletes or soccer professionals throughout a whole season would be a worthwhile next step to take in this line of research. The categories used in this study to identify tweet type provide a basis for possible future studies, but the issue of classifying the variable of mood or tone of tweet still requires subjective evaluation on the part of researchers. Data collection by more than one coder allowing to test inter coder reliability would help in solving this issue.

The high percentage of tweets written in languages other than German or English presented an unexpected barrier to analysis. Future studies should focus on translating and coding all tweets, regardless of language. This was beyond the capacity of the researchers carrying out this particular analysis, but could easily be remedied in future examinations of championship events in the sport of soccer. Indeed, cross-language comparison might allow for international comparisons between languages and/or countries of origin and the content of the tweets.

\subsection{Future research}

Future research should take a closer look at elite athletes' Twitter usage from the perspective of the consumer, rather than simply the player. A survey of Twitter followers to ascertain their reactions and attitudes towards particular players on Twitter and particular types of tweets would be useful from a scholarly perspective. Furthermore it 
would be relevant which kind of tweets evoke the highest user participation: ${ }^{10}$ Which messages are consistently retweeted? Which types of information are favoured?

The section of this paper focusing on the structure and potential of Twitter showed the popularity of the service in Spain, where Real Madrid's midfielders Cristiano Ronaldo and Kaka had garnered over 20 million followers each. When completing the undertaken study, the Spanish top clubs FC Barcelona and Real Madrid had between 7.7 and 9 million subscribers. A study that focused on elite Spanish football clubs and players might reveal similarities and differences between this country and others.

Barcelona's defender Gerard Piqué had about six million followers who surely explain the high amount of retweets he gets for his sent messages. Despite Pique's team losing to Bayern Munich in the semifinal, he sent a congratulatory tweet to the Champions League winners which were retweeted more than 8,600 times ("Congratulations to FC Bayern München. Best team in Europe this year. They deserve to win the Champions League." / Piqué, 25th May 2013).

\section{References}

Abeza, G., O’Reilly, N., Séguin, B. and Nzindukiyimana, O. (2015) 'Social media scholarship in sport management research: a critical review', Journal of Sport Management, Vol. 29, No. 6, pp.601-618.

Achen, R.M. (2015) 'Using Facebook and Twitter to encourage physical activity: are college students connecting with campus recreation on social media? A pilot study', Recreational Sports Journal, Vol. 39, No. 2, pp.132-143.

Ashby, K. (2013) Wembley-Finale Weltweit Verfolgt, 27 May [online] http://de.uefa.com/ uefachampionsleague/news/newsid=1957588.html (accessed 30 June 2015).

Bayne, K.S. and Cianfrone, B.A. (2013) 'The effectiveness of social media marketing: the impact of Facebook status updates on a campus recreation event', Recreational Sports Journal, Vol. 37, No. 2, pp.147-159.

Billings, A. (2014) 'Power in the reverberation: why Twitter matters, but not the way most believe', Communication and Sport, Vol. 2, No. 2, pp.107-112.

Bortree, D.S. (2005) 'Presentation of self on the web: an ethnographic study of teenage girls' web logs', Education, Communication and Information, Vol. 5, No. 1, pp.25-39.

Brison, N.T., Baker, T.A. and Byon, K.K. (2015) 'Facebook likes and sport brand image: an empirical examination of the national advertising division's coastal contacts' decision', Journal of Legal Aspects of Sport, Vol. 25, No. 2, pp.104-122.

Burk, V., Grimmer, C.G. and Pawlowski, T. (2016) 'Same, same - but different!' On consumers' use of corporate PR media in sports', Journal of Sport Management, Vol. 30, No. 4, pp.353-368.

Caplan, S.E. (2005) 'A social skill account of problematic internet use', Journal of Communication, Vol. 55, No. 4, pp.721-736.

Clavio, G. and Kian, E.M. (2010) 'Uses and gratifications of a retired female athlete's Twitter followers', International Journal of Sport Communication, Vol. 3, No. 4, pp.485-500.

Clavio, G. and Walsh, P. (2013) 'Dimensions of social media utilization among college sport fans', Communication and Sport, Vol. 2, No. 3, pp.261-281.

Eagleman, A.N. (2013) 'Acceptance, motivations, and usage of social media as a marketing communications tool amongst employees of sport national governing bodies', Sport Management Review, Vol. 16, No. 4, pp. 488-497. 
Frederick, E. and Clavio, G. (2015) 'Blurred lines: an examination of high school football recruits' self-presentation on Twitter', International Journal of Sport Communication, Vol. 8, No. 3, pp.330-344.

Frederick, E., Lim, C.H., Clavio, G., Pedersen, P.M. and Burch, L.M. (2014) 'Choosing between the one-way or two-way street: an exploration of relationship promotion by professional athletes on Twitter', Communication and Sport, Vol. 2, No. 1, pp.80-99.

Gibbs, J.L., Ellison, N.B. and Heino, R.D. (2006) 'Self-presentation in online personals: the role of anticipated future interaction, self-disclosure, and perceived success in internet dating', Communication Research, Vol. 33, No. 2, pp.152-177.

Goffman, E. (1959) The Presentation of Self in Everyday Life, Doubleday, New York.

Grimmer, C.G. (2014) Athlete Marketing and the Role of Social Media, 1 August [online] http://thescorecard.org/post/860 (accessed 2 March 2016).

Hambrick, M.E. (2012) 'Six degrees of information: using social network analysis to explore the spread of information within sport social networks', International Journal of Sport Communication, Vol. 5, No. 1, pp.16-34.

Hambrick, M.E. and Mahoney, T.Q. (2011) 'It's incredible - trust me': exploring the role of celebrity athletes as marketers in online social networks', International Journal of Sport Management and Marketing, Vol. 10, Nos. 3/4, pp.161-179.

Hambrick, M.E., Simmons, J.M., Greenhalgh, G.P. and Greenwell, T.C. (2010) 'Understanding professional athletes' use of Twitter: a content analysis of athlete tweets', International Journal of Sport Communication, Vol. 3, No. 4, pp.454-471.

Hambrick, M.E. and Svensson, P.G. (2015) 'Gainline Africa: a case study of sport-for-development organizations and the role of organizational relationship building via social media', International Journal of Sport Communication, Vol. 8, No. 2, pp.233-254.

Han, P., Dodds, M., Mahoney, T., Schoepfer, K. and Lovich, J. (2015) 'Regulating student-athlete's inappropriate social media usage', Case Studies in Sport Management, Vol. 4, No. 1, pp.7-13.

Haugh, B.R. and Watkins, B. (2016) 'Tag me, tweet me if you want to reach me: an investigation into how sports fans use social media', International Journal of Sport Communication, Vol. 9, No. 3, pp.278-293.

Hepper, E. (2009) Erfolgreiche Pressearbeit. Der souveräne Umgang mit den Medien, Dashöfer, Hamburg.

Hipke, M. and Hachtmann, F. (2014) 'Game changer: a case study of social-media strategy in big ten athletic departments', International Journal of Sport Communication, Vol. 7, No. 4, pp.516-532.

Hodge, C., Pederson, J.A. and Walker, M. (2015) 'How do you 'likel my style? Examining how communication style influences Facebook behaviors', International Journal of Sport Communication, Vol. 8, No. 3, pp.276-292.

Hogan, B. (2010) 'The presentation of self in the age of social media: distinguishing performances and exhibitions online', Bulletin of Science, Technology and Society, Vol. 30, No. 6, pp.377-386.

Hull, K. (2014a) 'A hole in one (hundred forty characters): a case study examining PGA tour golfers' Twitter use during the masters', International Journal of Sport Communication, Vol. 7, No. 2, pp.245-260

Hull, K. (2014b) '\#Fight4UNCWSwimandDive: a case study of how college athletes used Twitter to help save their teams', International Journal of Sport Communication, Vol. 7, No. 4, pp.533-552.

Jensen, J.A., Ervin, S.M. and Dittmore, S.W. (2014) 'Exploring the factors affecting popularity in social media: a case study of football bowl subdivision head coaches', International Journal of Sport Communication, Vol. 7, No. 2, pp.261-278. 
Kang, S. (2015) 'The mobile phone and professional sports: fans' use of mobile content for loyalty, identification, and fandom', International Journal of Sport Communication, Vol. 8, No. 4, pp.452-476.

Kang, S.J., Ha, J-P. and Hambrick, M.E. (2015) 'A mixed-method approach to exploring the motives of sport-related mobile applications among college students', Journal of Sport Management, Vol. 29, No. 3, pp.272-290.

Kaplan, A.M. and Haenlein, M. (2010) 'Users of the world, unite! The challenges and opportunities of social media', Business Horizons, Vol. 53, No. 1, pp.59-68.

Katz, E., Blumler, J.G. and Gurevitch, M. (1974) 'Utilization of mass communication by the individual', in Blumler, J.G. and Katz, E. (Eds.): Uses of Mass Communications, Vol. 3, pp.19-32, Sage, Beverly Hills/CA.

Kian, E.M. (2015) 'A case study on message-board and media framing of gay male athletes on a politically liberal web site', International Journal of Sport Communication, Vol. 8, No. 4, pp.500-518.

Kietzmann, J.H., Hermkens, K., McCarthy, I.P. and Silvestre, B.S. (2011) 'Social media? Get serious! Understanding the functional building blocks of social media', Business Horizons, Vol. 54, No. 3, pp.241-251.

Kwak, H., Lee, C., Park, H. and Moon, S. (2010) 'What is Twitter, a social network or a news media?', Paper presented at the 19th International World Wide Web Conference, Raleigh/NC, 26-30 April [online] http://an.kaist.ac.kr/ haewoon/papers/2010-www-twitter.pdf (accessed 22 March 2013).

Larkin, B. and McKelvey, S. (2015) 'Of smart phones and Facebook: social media's changing legal landscape provides cautionary tales of 'Pinterest' for sport organizations', Journal of Legal Aspects of Sport, Vol. 25, No. 2, pp.123-153.

Leary, M.R. and Kowalski, R.M. (1990) 'Impression management: a literature review and two-component model', Psychological Bulletin, Vol. 107, No. 1, pp.34-47.

Lebel, K. and Danylchuk, K. (2012) 'How tweet it is: a gendered analysis of professional tennis players' self-presentation on Twitter', International Journal of Sport Communication, Vol. 5, No. 4, pp.461-480.

Lebel, K., Danylchuk, K. and Millar, P. (2015) 'Social media as a learning tool: sport management faculty perceptions of digital pedagogies', Sport Management Education Journal, Vol. 9, No. 1, pp.39-50.

McMahon, J., McGannon, K.R. and Zehntner, C. (2016) 'Slim to win: an ethnodrama of three elite swimmers' 'presentation of self' in relation to a dominant cultural ideology', Sociology of Sport Journal, DOI: http://dx.doi.org/10.1123/ssj.2015-0166.

Miranda, F.J., Chamorro, A., Rubio, S. and Rodriguez, O. (2014) 'Professional sports teams on social networks: a comparative study employing the Facebook assessment index', International Journal of Sport Communication, Vol. 7, No. 1, pp.74-89.

Moritz, B. (2015) 'The story versus the stream: digital media's influence on newspaper sports journalism', International Journal of Sport Communication, Vol. 8, No. 4, pp.397-410.

Naraine, M.L. and Parent, M.M. (2016) 'Birds of a feather': an institutional approach to Canadian national sport organizations' social-media use', International Journal of Sport Communication, Vol. 9, No. 2, pp.140-162.

Nölleke, D., Grimmer, C.G. and Horky, T. (2016) 'News sources and follow-up communication - facets of complementarity between sports journalism and social media', Journalism Practice, DOI: 10.1080/17512786.2015.1125761.

Olushola, J.O. (2015) 'Sport, racism, and social media', International Journal of Sport Communication, Vol. 8, No. 2, pp.257-261.

Papacharissi, Z. (2002) 'The presentation of self in virtual life: characteristics of personal home pages', Journalism and Mass Communication Quarterly, Vol. 79, No. 3, pp.643-660. 
Pegoraro, A. (2010) 'Look who's talking - athletes on Twitter: a case study', International Journal of Sport Communication, Vol. 3, No. 4, pp.501-514.

Roberts, C. and Emmons, B. (2016) Twitter in the Press Box: how a new technology affects game-day routines of print-focused sports journalists', International Journal of Sport Communication, Vol. 9, No. 1, pp.97-115.

Rui, J. and Stefanone, M.A. (2013) 'Strategic self-presentation online: a cross-cultural study', Computers in Human Behavior, Vol. 29, No. 1, pp.110-118.

Sanderson, J. (2008) 'The blog is serving its purpose: self-presentation strategies on 38pitches.com', Journal of Computer-Mediated Communication, Vol. 13, No. 4, pp.912-936.

Sanderson, J. (2009) 'Professional athletes' shrinking privacy boundaries: fans, information and communication technologies, and athlete monitoring', International Journal of Sport Communication, Vol. 2, No. 2, pp.240-256.

Sanderson, J. (2011) It's a Whole New Ball Game: How Social Media is Changing Sports, Hampton Press, New York.

Sanderson, J. (2013) 'Stepping into the (social media) game: building athlete identity via Twitter', in Luppicini, R. (Ed.): Handbook of Research on Technoself: Identity in a Technological Society, pp.419-438, IGI Global, New York.

Sanderson, J. (2014) 'Just warming up: Logan Morrison, Twitter, athlete identity, and building the brand', in Brummett, B. and Ishak, A.W. (Eds.): Sport and Identity: New Agendas in Communication, pp.208-223, Routledge, New York.

Sanderson, J. and Browning, B. (2015) 'From the physical to the social: Twitter as a pedagogical innovation in the sport communication and sport management classroom', Sport Management Education Journal, Vol. 9, No. 2, pp.124-131.

Sanderson, J. and Gramlich, K. (2016) 'You go girl!': Twitter and conversations about sport culture and gender', Sociology of Sport Journal, Vol. 33, No. 2, pp.113-123.

Schierl, T. (2011) 'Der Star als marke, die marke als star' - anmerkungen zum aufbau und zur pflege von sportlermarken', in Schierl, T. and Schaaf, D. (Eds.): Sport und Werbung, pp.326-343, Herbert von Halem Verlag, Köln.

Schwier, J. and Leggewie, C. (2006) 'Medienfußball und medienpolitik - zwei seiten einer medaille?, in Schwier, J. and Leggewie, C. (Eds.): Wettbewerbsspiele. Die Inszenierung von Sport und Politik in den Medien, pp.7-19, Campus, Frankfurt/Main.

Scott, O.K.M. and Stanway, A.R. (2015) 'Tweeting the lecture: how social media can increase student engagement in higher education', Sport Management Education Journal, Vol. 9, No. 2, pp.91-101

Stelmaszyk, L. (2010) 'Schöne neue Sportwelt', Sponsors, Vol. 15, No. 5, pp.26-30.

Twittercounter.com (2014) Twitter Top 100: Most Followers, 30 October [online] http://twittercounter.com/pages/100 (accessed 1 July 2015).

Unger, S. (2012) Parteien und Politiker in sozialen Netzwerken, VS Verlag für Sozialwissenschaften, Wiesbaden.

Wakefield, K. (2016) 'Fan passion to predict attendance, media consumption, and social media behaviors', Journal of Sport Management, Vol. 30, No. 3, pp.229-247.

Walsh, P., Clavio, G., Lovell, M.D. and Blaszka, M. (2013) 'Differences in event brand personality between social media users and non-users', Sport Marketing Quarterly, Vol. 22, No. 4, pp.214-223.

Walsh, P. and Williams, A. (2016) 'To extend or not extend a human brand: an analysis of perceived fit and attitudes towards athlete brand extensions', Journal of Sport Management, DOI: http://dx.doi.org/10.1123/jsm.2015-0314.

Wang, Y. and Zhou, S. (2015) 'How do sports organizations use social media to build relationships? A content analysis of NBA clubs' Twitter use', International Journal of Sport Communication, Vol. 8, No. 2, pp.133-148. 
Watanabe, N., Yan, G. and Soebbing, B.P. (2015) 'Major league baseball and Twitter usage: the economics of social media use', Journal of Sport Management, Vol. 29, No. 6, pp.619-632.

Watanabe, N.M., Yan, G. and Soebbing, B.P. (2016) 'Consumer interest in major league baseball: an analytical modeling of Twitter', Journal of Sport Management, Vol. 30, No. 2, pp.207-220.

Weathers, M., Sanderson, J., Matthey, P., Grevious, A., Tehan, M. and Warren, S. (2014) 'The tweet life of Erin and Kirk: a gendered analysis of sports broadcasters' self-presentation on Twitter', Journal of Sports Media, Vol. 9, No. 2, pp.1-24.

\section{Notes}

1 Hepper (2009) identified five qualities and chances that the internet in its Web 2.0-era offers: velocity/actuality, interactivity (blogs, chats, forums), unlimited space, ubiquity (theoretically available anytime), universality (combining text, pics, audio and video).

2 To the following summary and the upcoming importance of social media especially with focus on sports, see Stelmaszyk (2010).

3 In contrast to Facebook with its rather social focus the social media-tool twitter is superficially information medium.

4 Twitter is called micro-blogging service because only 140 characters per tweet can be used. Because the messages have to be 'short and precise' [Unger, (2012), p.72; own translation], the communication channel requires the ability to say much with less words.

5 The former soccer international Patrick Owomoyela had a protected profile. A contact request to him has not been answered and therefore his account could not be analysed. But also in the case of confirmation the profile would not have been integrated in the study because the account is not in the same degree made for public like the other, open profiles.

6 Bayern Munich's midfielder Bastian Schweinsteiger sent his first tweet on 14th May 2013 - one day before the beginning of the analysis.

7 Data collection was applied by just a single coder. Thus, no inter coder reliability has been checked.

8 Compared to that, the victory in the German FA cup final seemed to be uninteresting: The day after winning the DFB-cup in Berlin each of the 14 Bayern twitterer sent 1.7 tweets on average. This is probably due to the motorcade and the subsequent celebration on Munich's Marienplatz with their fans, when the players seemed to have completely forgotten twittering. It is interesting that the FA cup peak occurred not the day after the event, but on match day and match day's night. Pleasant anticipation and celebration photos made possible an average of 2.1 tweets per professional.

9 Therefore the variables 'content' and 'mood' could not be coded. Same applies to tweets in further languages like Spanish and Portuguese. Both named variables 'content' and 'mood' have only been coded for German and English tweets.

10 The different forms of production theatricalisation, emotionalisation, personalisation and telegenisation could be helpful for characterising the kind of tweets [Schwier and Leggewie, (2006), pp.12-14]. The label medialisation can be an alternative for telegenisation, because that only means the sports' adaption to the television logic. 